\title{
Inheritance of Fruit Traits in Capsicum annuum: Heirloom Cultivars as Sources of Quality Parameters Relating to Pericarp Shape, Color, Thickness, and Total Soluble Solids
}

\author{
Lucianne Braga Oliveira Vilarinho \\ Horticultural Sciences Department, University of Florida, Gainesville, FL 32611-0690; and \\ Universidade Federal de Roraima, Avenida Capitao E Garcez, 2500, Aeroporto-Boa Vista 69304220, \\ RR-Brazil
}

Derly Jose Henriques da Silva

Horticultural Sciences Department, University of Florida, Gainesville, FL 32611-0690; and

Universidade Federal de Viçosa, Avenida P.H. Rolfs, S/N. Viçosa, 36570-000, MG-Brazil

Ann Greene, Kara Denee Salazar, Cristiane Alves, Molly Eveleth, and Ben Nichols

Horticultural Sciences Department, University of Florida, Gainesville, FL 32611-0690

\begin{abstract}
Sana Tehseen
Horticultural Sciences Department, University of Florida, Gainesville, FL 32611-0690; and

Department of Horticulture, University of Agriculture, Faisalabad, Pakistan
\end{abstract}

Joseph Kalil Khoury Jr.

Universidade Federal de Viçosa, Avenida P.H. Rolfs, S/N. Viçosa, 36570-000, MG-Brazil

Jodie V. Johnson

Chemistry Department, Spectroscopy Services, University of Florida, Gainesville, FL 32611-7200

\author{
Steven A. Sargent and Bala Rathinasabapathi ${ }^{1}$ \\ Horticultural Sciences Department, University of Florida, Gainesville, FL 32611-0690
}

\begin{abstract}
AdDitional INDEX WORDs. antioxidants, carotenoids, fruit morphology, pepper, Solanaceae, vegetable breeding
ABSTRACт. Inheritance of fruit-related traits was studied in a population generated by crossing two heirloom pepper (Capsicum annuum) cultivars, Round of Hungary and Bulgarian carrot. Inheritance of corrugated pericarp phenotype of 'Round of Hungary' behaved as a recessive trait controlled by two genes while round fruit shape behaved as a single gene. Pungent cultivar Bulgarian carrot had significantly higher total soluble solids, titratable acidity, antioxidant activities, and significantly thinner pericarp than fruit of Round of Hungary. Pericarp thickness was related to differences in both cell number and cell size. Analyses of $F_{2}$ fruit indicated that fruit weight was positively correlated $(P<0.01)$ to fruit width and pericarp thickness. Fruit width was negatively correlated $(P<0.01)$ to fruit length and total soluble solids and positively correlated $(P<0.01)$ to pericarp thickness. Yellow color was negatively correlated $(P<0.05)$ to total soluble solids. Fruit length showed high inbreeding depression and transgressive segregation. Color measurements showed that yellow was correlated to lightness, and the relationships between red and yellow color spaces and carotenoid composition were complex.
\end{abstract}

Capsicum annuum, a vegetable crop of international importance, has rich genetic diversity for fruit traits. Much of this diversity has been exploited to develop sweet, blocky peppers that are most popular in commercial production and typically harvested at the green (immature) stage (Crosby, 2008). Recently,

Received for publication 15 July 2015. Accepted for publication 28 Sept. 2015. We thank the College of Agriculture and Life Sciences, University of Florida, for a teaching mini-grant to BR, CAPES/Brazil for a scholarship to LV and JK; and CNPq for a scholarship to DS. We acknowledge the following University of Florida students for their help with plant care and data collection as part of the "Building Better Peppers" initiative: Ana Julia Alcantara, Tyler Baras, Jose D. Castano, Sarah Dickerson, Adriana Clinton, Sean Rider, Ed Viera, Rachel Wallace, and Zachary Winkler and Marisol Amador for photography.

${ }^{1}$ Corresponding author. E-mail: brath@ufl.edu. a class of sweet pepper types harvested at ripe stage (full color) has gained popularity in the U.S. retail market and are marketed as "stoplight peppers," "sweet minis," and "lunchbox snack peppers." Colored sweet peppers are recognized for their visual appeal, sweet flavor, antioxidant activities, nutritive carotenoids, and anti-inflammatory compounds (Park et al., 2012; Sancho et al., 2002; Sun et al., 2007). We have initiated a program at the University of Florida to develop specialty pepper cultivars with improved quality related to shape, color, flavor, and health-promoting phytochemicals.

Although previous genetic research has revealed the inheritance of many horticultural traits in C. annuum (Ben-Chaim and Paran, 2000; Deshpande, 1933; Khambanonda, 1950; McArdle and Bouwkamp, 1983; Peterson, 1959; Wang and Bosland, 
2006), certain traits relevant to fruit development and quality have not been examined. Studies on the inheritance of fruit quality traits are needed to devise breeding programs to tailor specific traits. Research on fruit development in peppers can be expected to contribute to our understanding of fleshy fruit evolution in the Solanaceae and provide valuable insights into the genetics of commercially important traits (Tanksley, 2004; Tomato Genome Consortium, 2012). Because heirloom cultivars could be sources of desirable traits lacking in modern cultivars, we examined the inheritance of fruit traits in a population derived by crossing two contrasting, open-pollinated heirloom cultivars of $C$. annuит. This study confirms previous data on inheritance of fruit morphometric parameters and adds new data on the inheritance of pericarp shape, thickness, antioxidant potentials, and total soluble solids.

\section{Materials and Methods}

Plant material and cultivation conditions. Seeds of C. annuum cultivars Bulgarian carrot and Round of Hungary were purchased from Park Seed Co. (Greenwood, SC) and Johnny's Selected Seeds (Winslow, ME), respectively. The plants generated from these seed lots were uniform and had distinct heritable traits such as ripe fruit color, pungency, and fruit shape. Plants were grown in 11.4-L plastic containers in a temperature-controlled greenhouse at the University of Florida, Gainesville, FL. The cross 'Bulgarian carrot' $\times$ 'Round of Hungary' was made during Nov. 2010. $F_{1}$ seeds of a single fruit were harvested and grown in 11.4-L plastic containers during Spring 2011 and selfed to generate an $\mathrm{F}_{2}$ population.

$\mathrm{F}_{2}, \mathrm{~F}_{1}$, and parental line seeds were sown in transplant trays kept under a light bench with $112 \mu \mathrm{mol} \cdot \mathrm{m}^{2} \cdot \mathrm{s}^{-1}$ cool white fluorescent light set at $16 \mathrm{~h}$ light/dark cycle at $24{ }^{\circ} \mathrm{C}$ for 3 weeks. In Mar. 2012, the seedlings were transferred, one plant per 3.8-L plastic bag containing commercial potting medium (Fafard no. 2; Fafard, Agawam, MA) amended with $19 \mathrm{~N}-2.6 \mathrm{P}-$ 9.7K slow-release fertilizer (Osmocote; ScottsMiracle-Gro Co., Marysville, $\mathrm{OH})$. To evaluate the segregation of morphological traits, $118 \mathrm{~F}_{2}$ seedlings and five plants each of the parents and $\mathrm{F}_{1}$ hybrid were grown in the greenhouse in Gainesville. The greenhouse temperatures ranged between 16 and $38^{\circ} \mathrm{C}$ during the period of Apr. to Aug. 2012. Standard and uniform culture conditions of pest control and irrigation schedules were followed.

Evaluation of FRUIT TRAITs. The fruit were harvested when $100 \%$ of the fruit surface completed ripening as indicated by color change and at three different dates between mid-July and mid-Aug. 2012. At least three representative fruit from each plant were evaluated.

Biometrics DATA. The harvested fruit were analyzed for fruit length, fruit width, and pericarp thickness (in millimeters) at the equator using a digital caliper. Postharvest water loss was determined by weighing individual fruit immediately after harvest and again following 7-d storage in an open tray at room temperature $\left(25\right.$ to $27{ }^{\circ} \mathrm{C}$ ) and $55 \%$ to $60 \%$ relative humidity. Three fruit per plant were measured.

Fruit Quality evaluations. Total soluble solids of juice obtained by squeezing pericarp pieces in a garlic press were measured using a calibrated refractometer (Reichert Analytical, Buffalo, NY). Total titratable acidity was determined in pericarp tissue macerated in distilled water $[5 \mathrm{~g}$ fresh weight $(\mathrm{FW})$ in $10 \mathrm{~mL}$ water], by titrating it against freshly prepared $0.1 \mathrm{~N} \mathrm{NaOH}$ to an endpoint of $\mathrm{pH} \mathrm{8.2}$. Fruit color was measured using a color meter (CR-400; Konica Minolta Sensing Americas, Ramsey, NJ). Three fruit per plant and one measurement per fruit at the equator were done for these analyses.

Pericarp Microscopy. Wet mounts of pericarp sections ( 2 to $4 \mu \mathrm{m}$ thick) were examined without staining under a compound microscope (Eclipse E200; Nikon, Melvile, NY) and photographed using a digital camera (CoolPix E990; Nikon) fitted to the microscope.

Total antioxidant aCtivity assays. Pericarp samples $(1 \mathrm{~g})$ derived from freshly harvested ripe fruit (four fruit per sample from the parental lines) were frozen in liquid nitrogen and extracted in $4 \mathrm{~mL}$ water with acid-washed sand in a mortar and pestle. The brei was centrifuged at $10,000 \mathrm{~g}$ for $10 \mathrm{~min}$ and the

Table 1. Qualitative differences between ripened fruit of Capsicum annuum heirloom cultivars Round of Hungary (ROH) and Bulgarian carrot (BUC) and the $\mathrm{F}_{1}$.

\begin{tabular}{llll}
\hline Trait & ROH & BUC & \\
\hline Fruit color at maturity & Red & Orange yellow & $\mathrm{F}_{1}$ \\
Fruit shape & Round & Elongated & Red \\
Fruit texture & Corrugated & Noncorrugated & Slightly corrugated \\
Pungency & None & Highly pungent & Highly pungent \\
\hline
\end{tabular}

Table 2. Fruit morphometric traits, total soluble solids (TSS) (at harvest) and water loss after 1 week in fully ripe fruit of Capsicum annuum 'Bulgarian carrot' (BUC), 'Round of Hungary' (ROH), $\mathrm{F}_{1}$, and $\mathrm{F}_{2}$ population. Data are from at least three representative fruit per plant, five plants each of $F_{1}$ and the parents and $118 \mathrm{~F}_{2}$ plants. Means of quantitative data are shown with SD in parentheses.

\begin{tabular}{|c|c|c|c|c|c|}
\hline \multirow[b]{2}{*}{ Parameter } & \multirow[b]{2}{*}{ Unit } & $\mathrm{BUC}$ & $\mathrm{ROH}$ & $\mathrm{F}_{1}$ & $\mathrm{~F}_{2}$ \\
\hline & & \multicolumn{4}{|c|}{ Mean (SD) } \\
\hline Fruit weight & $\mathrm{g} /$ fruit & $10.13(1.45)$ & $60.16(99.80)$ & $29.01(20.92)$ & $31.85(8.11)$ \\
\hline Fruit length & $\mathrm{mm}$ & $74.79(18.32)$ & $34.45(9.6)$ & $64.40(41.19)$ & $55.23(20.48)$ \\
\hline Pericarp thickness & $\mathrm{mm}$ & $1.21(0.17)$ & $4.73(1.06)$ & $3.68(1.24)$ & $3.14(1.14)$ \\
\hline TSS & $\%$ & $10.68(6.5)$ & $7.73(0.16)$ & $7.68(0.65)$ & $7.36(1.95)$ \\
\hline Water loss in $7 \mathrm{~d}$ & $\mathrm{~g} /$ fruit & $3.5(0.8)$ & $14.7(2.3)$ & $6.7(0.5)$ & $5.7(2.4)$ \\
\hline
\end{tabular}




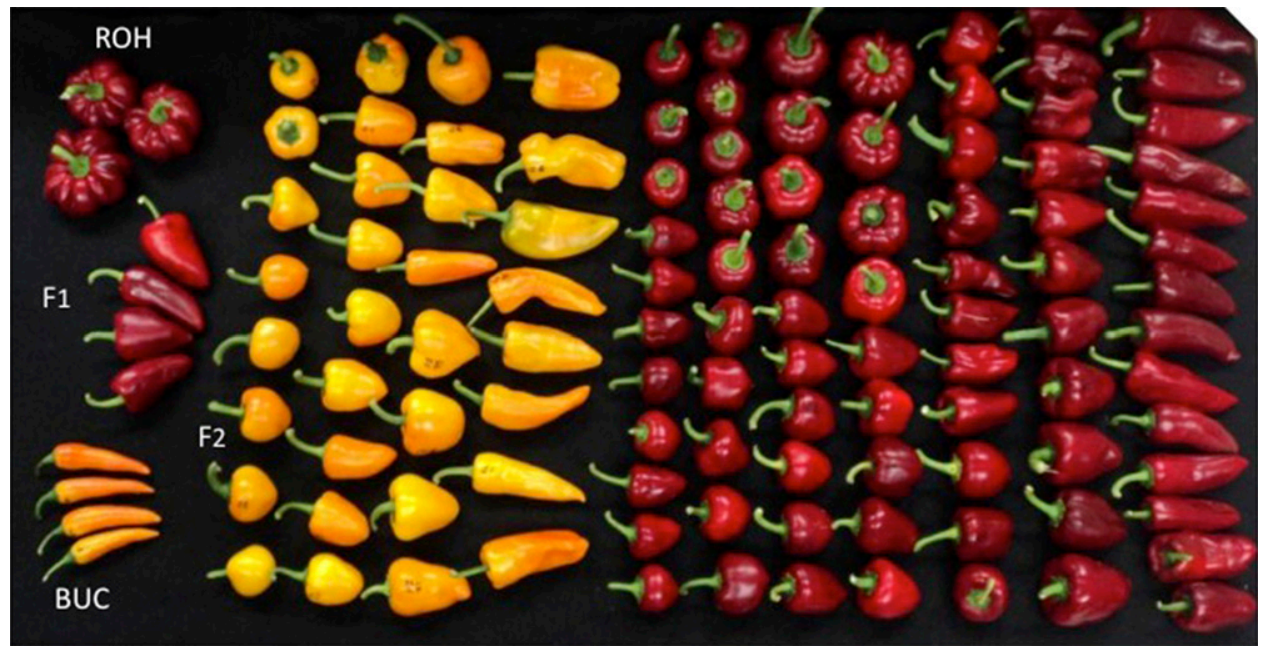

Fig. 1. Morphology of ripe fruit from Capsicum annuum genotypes 'Bulgarian carrot' (BUC), 'Round of Hungary' $(\mathrm{ROH})$, and their $\mathrm{F}_{1}$ and from each of $109 \mathrm{~F}_{2}$ plants.

\section{(A) BUC}

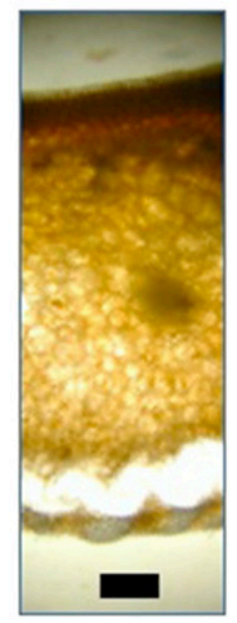

(B) $\mathrm{ROH}$

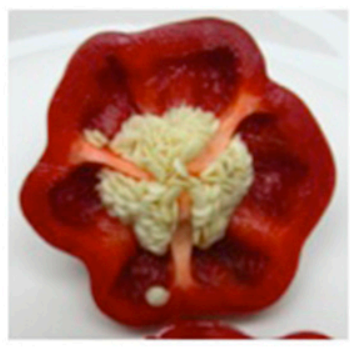

(C) $\mathrm{ROH}$

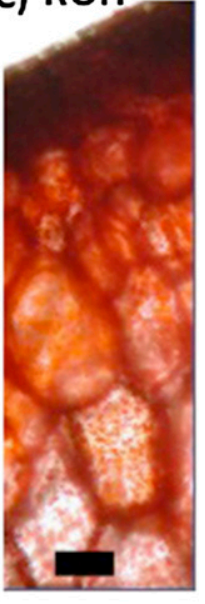

Fig. 2. Pericarp structure from ripe fruit of Capsicum annuum 'Bulgarian carrot' (BUC) (A) and 'Round of Hungary' $(\mathrm{ROH})(\mathbf{C})$. Pericarp sections $(2 \mu \mathrm{m}$ thick) were photographed without staining. (B) Cross-section of fruit of $\mathrm{ROH}$ illustrating the corrugated pericarp. The bars in $(\mathbf{A})$ and $(\mathbf{C})$ are $10 \mu \mathrm{m}$ long.

supernatant was collected. The pellet was reextracted with $2 \mathrm{~mL}$ water, and the aqueous extracts were pooled. The total antioxidant activity was measured in these extracts in triplicate samples by using the ferric reduction assay quantifying color change of ferric tripyridyltriazine at $593 \mathrm{~nm}$ as it is reduced by antioxidants in the sample (Benzie and Strain, 1996). Ascorbic acid was used as a standard for this assay.

Extraction AND ANAlysis of CARotenoids. Pericarp tissue ( $5 \mathrm{~g} \mathrm{FW}$ ) from freshly harvested completely ripe fruit of 'Round of Hungary' and 'Bulgarian carrot' were extracted using the method of López-Raéz et al. (2008). Extracts were analyzed using a reverse phase gradient high-performance liquid chromatography (HPLC) followed by (+)electrospray ionization (ESI)-mass spectrometry (MS). The HPLC (1100 series binary pump; Agilent, Palo Alto, CA) fitted with a Hypurity C8 column $(2.1 \times 100 \mathrm{~mm}+$ guard column; Thermoscientific, Waltham, MA) was eluted using a gradient of solvent mixtures $\mathrm{A}$ and $\mathrm{B}$ at 0.2
$\mathrm{mL} \cdot \mathrm{min}^{-1}$ with a gradient of $\mathrm{A}: \mathrm{B}$ $(\min )=70: 30(0)>15: 85$ (18) $>0: 100$ (58-80). Mobile phase A was $0.2 \%$ acetic acid in water and $\mathrm{B}$ was $0.2 \%$ acetic acid in methanol. While the HPLC detector was set at $450 \mathrm{~nm}$, the mass spectral analyses on the separated carotenoids were done using a liquid chromatography LCQ Classic quadrupole ion trap mass spectrometer (ThermoFinnigan, San Jose, CA) with ESI set with the following parameters ESI $(+)$ ESI: sheath gas $\left(\mathrm{N}_{2}\right)=65$; aux gas $\left(\mathrm{N}_{2}\right)=5$; heated capillary temperature $=250{ }^{\circ} \mathrm{C}$; spray tip voltage at $3.3 \mathrm{kV}$, heated capillary voltage at $+30 \mathrm{~V}$, and tube lens offset of $0 \mathrm{~V}$. Four different $\mathrm{m} / \mathrm{z}$ ranges were scanned to cover lower $\mathrm{m} / \mathrm{z}$ fragment ions and compounds $(\mathrm{m} / \mathrm{z}$ 125-270, 260-530), the carotenoids (m/z 520-600), and the xanthophyll esters and diesters (m/z 640-1200). In addition, scans were done, which isolated a particular ion with $5-\mathrm{m} / \mathrm{z}$ wide window but did not dissociate the ion. The molecular weight (MW) 536 and 568 carotenoids tended to produce $\mathrm{m} / \mathrm{z}$ 536 and m/z 568 molecular-type ions, respectively, but also some $\mathrm{m} / \mathrm{z} 569$ for the MW 568. The xanthophylls tended to produce $[\mathrm{M}+\mathrm{H}]^{+}$ions but they also produced ions due to loss of $\mathrm{H}_{2} \mathrm{O}$, i.e., $\left[\mathrm{M}+\mathrm{H}-\mathrm{H}_{2} \mathrm{O}\right]^{+}$. Xanthophyll esters of capsorubin and capsanthin were identified based on their HPLC-MS detection, their expected $[\mathrm{M}+\mathrm{H}]^{+}$ions with $450-\mathrm{nm}$ peaks in the retention time window expected for them. The $(+)$ ESI$\operatorname{MSn}(\mathrm{n}=1,2$, and 3$)$ were obtained on some of the xanthophyll diesters to confirm identity.

Statistical analysis. Quantitative data were plotted and evaluated by calculating means, variances, SD of the means, and Pearson correlation coefficients using the SAS statistical package (version 9.4; SAS Institute, Cary, NC). Estimates for genetic parameters for heterosis, inbreeding depression, inbreeding effect, average dominance level, heritability, and the approximate number of genes controlling a trait were done using the SAS program according to procedures described by Sharma (1988). The following equations were used, where $M$ refers to the mean value, $\mathrm{P}$ refers to the parents of the cross, and $\mathrm{V}$ variance. Heterosis $=\mathrm{MF}_{1}-\left(\mathrm{MP}_{1}+\mathrm{MP}_{2}\right) / 2$; inbreeding depression $=\mathrm{MF}_{1}-\mathrm{MF}_{2}$; inbreeding effect $=\left[\left(\mathrm{MF}_{1}-\mathrm{MF}_{2}\right) /\right.$ $\left.\mathrm{MF}_{1}\right] \times 100$; average dominance level $=\left(\mathrm{VF}_{1}-\mathrm{VP}\right) /\left(\mathrm{VP}_{1}-\right.$ $\mathrm{VP})$; heritability $=\left(\mathrm{VF}_{2}-\mathrm{V}_{\mathrm{E}}\right) /\left(\mathrm{V}_{\mathrm{E}}\right) ; \mathrm{V}_{\mathrm{E}}$ was calculated as the mean of variances from parent and $\mathrm{F}_{1}$ populations. The number of genes controlling a trait $\mathrm{n}=\left[0.25 \times\left(0.75-\mathrm{h}+\mathrm{h}^{2}\right)\right] \times\left(\mathrm{MP}_{1}-\right.$ $\left.\mathrm{MP}_{2}\right)^{2} /\left(\mathrm{VF}_{2}-\mathrm{VF}_{1}\right)$, where $\mathrm{h}=\left(\mathrm{MF}_{1}-\mathrm{MP}_{1}\right) /\left[\max \left(\mathrm{MP}_{1} ; \mathrm{MP}_{2}\right)-\right.$ $\left.\min \left(\mathrm{MP}_{1} ; \mathrm{MP}_{2}\right)\right] ; \mathrm{n} 1=\left(\mathrm{MP}_{1}-\mathrm{MP}_{2}\right)^{2} / \mathrm{abs}\left[8 \times\left(\mathrm{VF}_{2}-\mathrm{VF}_{1}\right)\right]$. Regression analyses were done using Excel (version 2013: Microsoft, Redmond, WA).

\section{Results}

The heirloom cultivars used in this study differed in a number of traits important in determining fruit quality (Tables 1 and 2; Fig. 1). Round of Hungary cultivar had fruit with a fleshy, corrugated pericarp resulting in a pumpkin-like fruit 
shape (Fig. 2B) whereas 'Bulgarian carrot' fruit had thinner pericarps (Table 2) without corrugations. The corrugated pericarp phenotype appeared to have resulted from the reduction of pericarp expansion (creation of "troughs") where

Table 3. Goodness of fit to a 1:14:1 phenotypic segregation ratio for fruit texture in $107 \mathrm{~F}_{2}$ Capsicum annuum plants from the cross 'Bulgarian carrot' $\times$ 'Round of Hungary' $(\mathrm{ROH})$. Chi-square at $2 \mathrm{df}$ at $P=0.05$ was 5.99, value greater than the calculated $\chi^{2}$ of 2.1264 . Fruit with no visible lobes were classified "smooth," those with a wavy pericarp with deep lobes as in ROH were classified "corrugated," and those with lobes less than 50\% deeper than that found in ROH were classified as "slightly corrugated."

\begin{tabular}{lccc}
\hline & Smooth & Slightly corrugated & Corrugated \\
\hline Observed & 10 & 89 & 8 \\
Expected & 6.6875 & 93.625 & 6.6875 \\
$\chi^{2}$ & 1.6408 & 0.228 & 0.2576 \\
\hline
\end{tabular}

Table 4. Phenotypes of Capsicum annuum fruit shape trait in $108 \mathrm{~F}_{2}$ plants. Chi-square at $2 \mathrm{df}$ at $P=0.05$ was 5.99 , value greater than the calculated value ( $\chi^{2}$ calc.) of 5.579. The length:width ratios of fruit classified as "round" ranged from 0.48 to 1.22 , as "long" ranged from 2.2 to 6.49 , and the "intermediate" ranged from 1.1 to 2.4 .

\begin{tabular}{llcc}
\hline & Round & Intermediate & Long \\
\hline Observed & 20 & 67 & 21 \\
Expected & 27 & 54 & 27 \\
$\chi^{2}$ & 1.565 & 2.894 & 1.120 \\
\hline
\end{tabular}

Table 5. Estimated genetic parameters for the inheritance of fruit morphometric traits in Capsicum annuum derived from data collected on parental lines, $\mathrm{F}_{1}$, and $\mathrm{F}_{2}$ of cross 'Bulgarian carrot' $\times$ 'Round of Hungary'.

\begin{tabular}{lrrrcr}
\hline Parameter & Wt & Length & Width & TSS & PT \\
\hline Heterozygosity & -6.13 & 9.78 & -6.13 & -1.53 & 0.71 \\
Inbreeding depression & -2.83 & 9.17 & -5.99 & 0.32 & 0.54 \\
Inbreeding effect & -9.77 & 14.24 & -18.01 & 4.14 & 14.59 \\
Average dominance level & 1.12 & 0.93 & 1.22 & 0.91 & 0.93 \\
Heritability & 0.60 & 17.05 & 0.04 & 0.5 & 0.52 \\
Genetic variance & 10.58 & 275.86 & -21.17 & 0.24 & 0.46 \\
$\mathrm{n}$ & 11.30 & 0.62 & 5.50 & 0.45 & 31.11 \\
$\mathrm{n}_{1}$ & 6.97 & 0.54 & 2.99 & 0.35 & 25.06 \\
\hline
\end{tabular}

PT $=$ pericarp thickness; TSS $=$ total soluble solids. locular walls were attached to the pericarp (Fig. 2B). Fruit from the $F_{1}$ was slightly corrugated (Fig. 1) and the $F_{2}$ population segregated for this trait (Fig. 1), fitting a model for two recessive genes controlling the fully corrugated pericarp phenotype and one recessive gene resulting in slightly corrugated phenotype (Table 3 ).

Microscopic observations of pericarp sections indicated that the two cultivars did not differ in the thickness of the cuticular wax layer (data not shown). When pericarp sections from eight independent fruit were examined for each cultivar, 'Round of Hungary' pericarp had a mean $( \pm \mathrm{SE})$ of $28 \pm 1.1$ layers of cells while 'Bulgarian carrot' fruit had a mean of $23.1 \pm 0.6$. 'Round of Hungary' pericarp cells were larger in size than those of 'Bulgarian carrot' fruit (Fig. 2A and C). In both cultivars, the densities of chromoplasts were greater in cells closer to the outer epidermis and progressively decreased toward the inner epidermis (Fig. 2A and C). When fruit shape was scored qualitatively as round and long, the $\mathrm{F}_{2}$ population segregated as single gene with the round phenotype being incompletely dominant (Table 4; Fig. 1).

Estimates of genetic parameters suggested that there was high heterozygosity for fruit length, but no heterotic effect for fruit weight, fruit width, total soluble solids, or pericarp thickness (Table 5). On the other hand, inbreeding effect was in the negative direction for fruit weight and fruit width (Table 5 ). Both the genetic variance and heritability were lower for fruit width but high for fruit length (Table 5). It was estimated that the fruit weight, fruit width, and pericarp thickness were controlled by $>7$ genes (Table 5).

To find potential relationships between fruit geometric parameters and their potential relationship to fruit weight, total soluble solids, and fruit color, a matrix of Pearson correlation coefficients was calculated. The data indicated that fruit $\mathrm{FW}$ was positively correlated to fruit width and pericarp thickness (Table 6). Fruit length was negatively correlated to fruit width $(P<0.01)$. Total soluble solids were positively correlated to fruit length and negatively to fruit width $(P<0.01)$. Pericarp thickness was positively correlated to fruit FW (Table 6). None of the color measurements were correlated to morphometric values of the fruit. However, $\mathrm{L}^{*}$ (lightness) of the color was highly correlated to the yellow color space measurement, while the red color $\left(+\mathrm{a}^{*}\right)$ was negatively correlated to yellow color $\left(+b^{*}\right)$. The yellow color was negatively correlated to the total soluble solids (Table 6).

Table 6. Pearson correlation coefficient matrix for analyses of quantitative parameters related to fruit quality in the $F_{2}$ population from 'Bulgarian carrot' $\times$ 'Round of Hungary' cross of Capsicum annuum. Weight, length, and width refer to means of fruit fresh weight, length, and width, respectively.

\begin{tabular}{|c|c|c|c|c|c|c|c|c|}
\hline & $\mathrm{Wt}$ & Length & Width & TSS & PT & $\mathrm{L}^{* \mathrm{z}}$ & $a^{* z}$ & $b^{* z}$ \\
\hline Weight & & -0.0423 & $0.6276 * *$ & -0.1337 & $0.3207 * *$ & -0.1138 & 0.0580 & -0.1607 \\
\hline Length & -0.0423 & & $-0.3628 * *$ & 0.3507 & -0.1661 & 0.0305 & -0.0288 & 0.0026 \\
\hline Width & 0.6276 & $-0.3628 * *$ & & $-0.3415 * *$ & $0.2544 *$ & -0.1499 & 0.0195 & -0.1469 \\
\hline PT & $0.3207 * *$ & -0.1661 & $0.2544 * *$ & -0.0222 & & -0.0601 & 0.0528 & -0.0939 \\
\hline $\mathrm{L}$ & -0.1138 & 0.0305 & -0.1499 & -0.2227 & -0.0601 & & -0.1061 & $0.9120 * *$ \\
\hline$a^{*}$ & 0.0580 & -0.0288 & 0.0195 & 0.0913 & 0.0528 & -0.1061 & & $-0.3307 * *$ \\
\hline
\end{tabular}

TSS $=$ total soluble solids; PT $=$ pericarp thickness.

${ }^{\mathrm{z}} \mathrm{L}^{*},+\mathrm{a}^{*}$, and $+\mathrm{b}^{*}$ are color space parameters referring to lightness, red, and yellow, respectively.

$*$, **Correlations significant at $P<0.05$ and $<0.01$, respectively, and were shown in bold. 

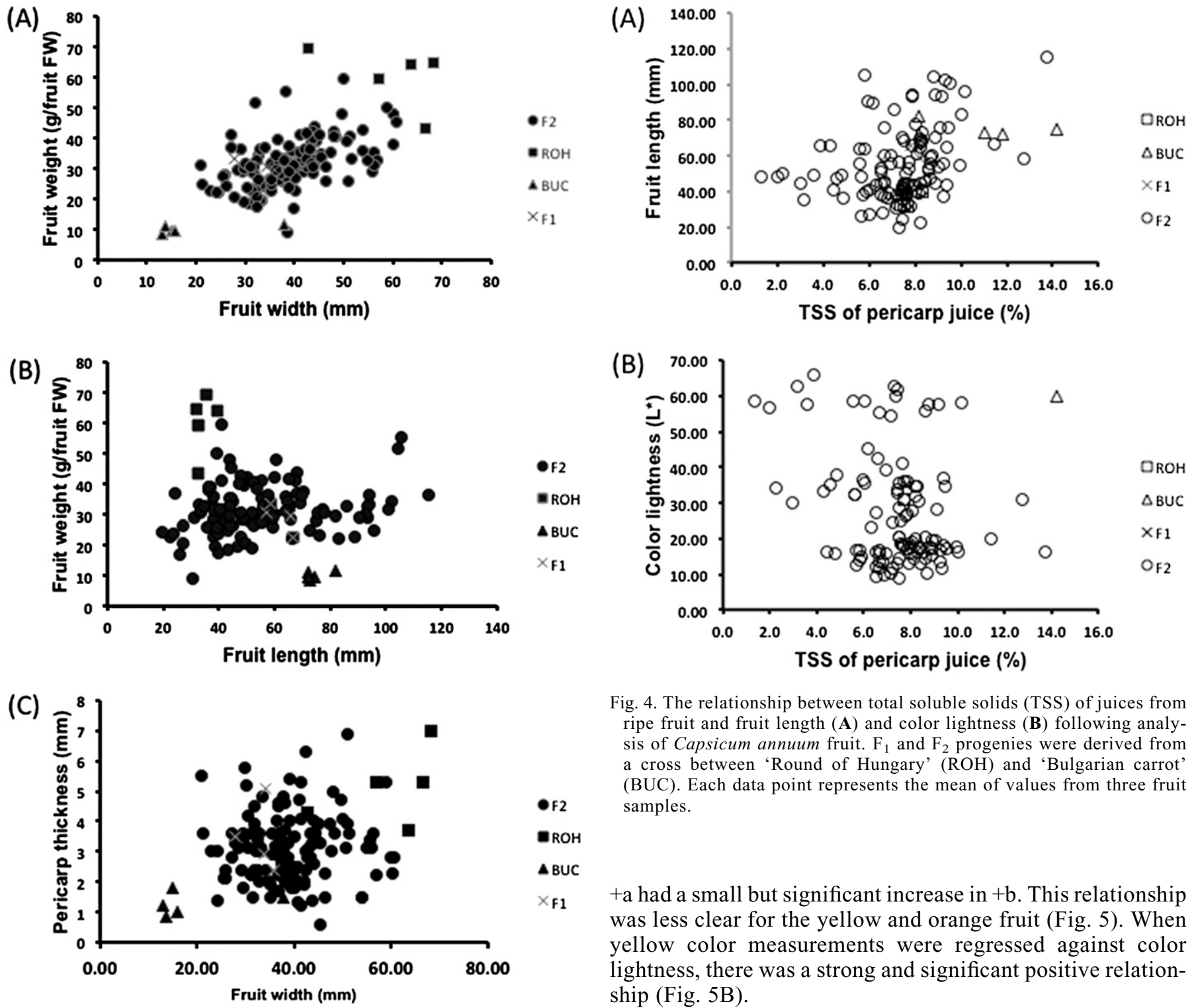

Fig. 4. The relationship between total soluble solids (TSS) of juices from ripe fruit and fruit length (A) and color lightness (B) following analysis of Capsicum annuum fruit. $\mathrm{F}_{1}$ and $\mathrm{F}_{2}$ progenies were derived from a cross between 'Round of Hungary' (ROH) and 'Bulgarian carrot' (BUC). Each data point represents the mean of values from three fruit

ROH

$\triangle$ BUC

Fig. 3. The relationships between morphometric traits of ripe fruit of Capsicum annuum in the $\mathrm{F}_{2}$ population compared with that of parents and $\mathrm{F}_{1}$. Relationships between fruit width and fruit weight (A), fruit length and fruit weight (B), and fruit width and pericarp thickness $(\mathbf{C})$ are shown. $\mathrm{F}_{1}$ and $\mathrm{F}_{2}$ progenies were derived from a cross between ('Round of Hungary') ROH and 'Bulgarian carrot' (BUC). Each data point represents the mean of values from three fruit samples.

To explore these significant correlations, we examined scatter plots of values of these parameters. Fruit width was linearly dependent on fruit weight (Fig. 3A), but not fruit length (Fig. 3B). Fruit length measurements in $F_{2}$ showed that there was transgressive variation for this trait (Fig. 3B). Fruit width was positively related to pericarp thickness (Fig. 3C). As fruit length increased, the total soluble solids in the pericarp juice increased (Fig. 4A), but the relationship between the lightness of color and total soluble solids was negative but more complex (Fig. 4B; Table 6).

When red color values $\left(+\mathrm{a}^{*}\right)$ were regressed against yellow $\left(+b^{*}\right)$ measurements, the data points clustered into two groups (Fig. 5A). In the fruit that were red, an increase in samples.

$$
\text { samples. }
$$

$+a$ had a small but significant increase in $+b$. This relationship was less clear for the yellow and orange fruit (Fig. 5). When yellow color measurements were regressed against color lightness, there was a strong and significant positive relationship (Fig. 5B).

The two cultivars studied here did not differ significantly for water loss per gram initial weight of the fruit (data not shown), but larger fruit lost greater amount of water per fruit $\left(r^{2}=0.396\right.$, significant at $P=0.05$ ).

Aqueous extracts of 'Bulgarian carrot' pericarp had significantly greater total antioxidant capacity than the pericarp extracts of 'Round of Hungary' [399.87 \pm 110.53 vs. $182.63 \pm 3.43 \mathrm{nmol}$ ascorbic acid equivalents per gram FW (mean $\pm \mathrm{SE}$ ), respectively]. The $\mathrm{F}_{1}$ fruit had an intermediate level of $286.15 \pm 63.5 \mathrm{nmol}$ ascorbic acid equivalents per gram $\mathrm{FW}$.

A carotenoid analysis of pericarps from 'Round of Hungary' and 'Bulgarian carrot' showed that the red carotenoids capsorubin and capsanthin and their mono and diesters with fatty acids were more abundant in the red 'Round of Hungary' compared with the yellow fruit of 'Bulgarian carrot' (Table 7). Capsanthin monoester (MW 794) was the one that distinguished 'Round of Hungary' from 'Bulgarian carrot' most. However, several other carotenoids (possibly conferring yellow and orange coloration) including some forms of capsanthin were more abundant in 'Bulgarian carrot' and six of them were unique to this genotype (Table 7). 

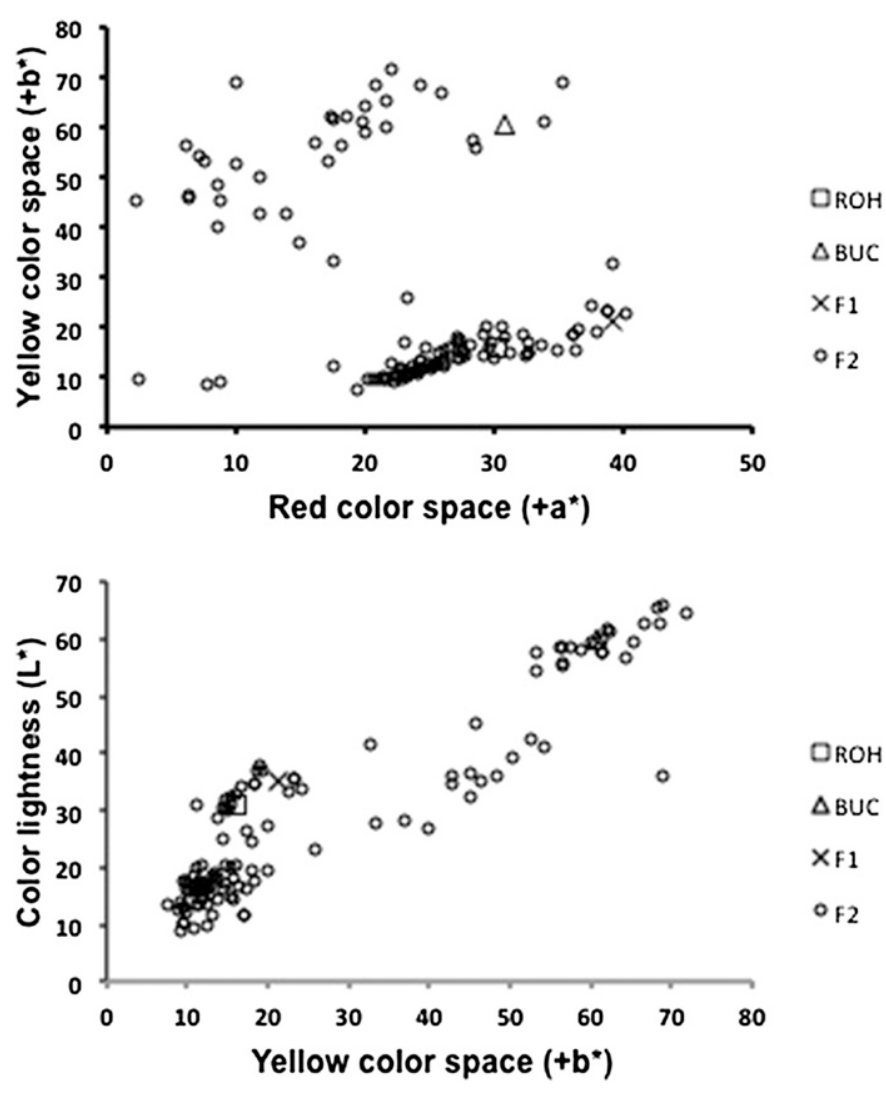

Fig. 5. Relationships between color parameters measured in ripe fruit surfaces in Capsicum annuum fruit. Values of red color space $\left(+\mathrm{a}^{*}\right)$ were plotted against yellow color space $\left(+b^{*}\right)(A)$ and values of yellow color space against color lightness $\left(\mathrm{L}^{*}\right)$ (B). $\mathrm{F}_{1}$ and $\mathrm{F}_{2}$ progenies were derived from a cross between 'Round of Hungary' (ROH) and 'Bulgarian carrot' (BUC). Each data point represents the mean of values from three fruit samples.

\section{Discussion}

This study was designed to identify the inheritance of selected fruit quality-related traits within $C$. annuum by crossing cultivars differing in a number of traits (Tables 1 and 2; Fig. 1). These traits included fruit weight, width, length, pericarp corrugation, fruit overall shape, pericarp thickness, total soluble solids, and fruit color at maturity (Table 2). Although the data on fruit quality presented here were from plants grown in a single greenhouse environment and of a limited population size, they can be cautiously compared with other studies to make useful inferences and are applicable under greenhouse production of color peppers. Our results showed significantly higher levels of antioxidant activity, pungency, and total soluble solids in the extracts of 'Bulgarian carrot' fruit compared with the fruit of 'Round of Hungary' (Tables 1 and 2). A preliminary evaluation of ripe fruit extracts showed the 'Bulgarian carrot' fruit had higher acidity than the fruit of 'Round of Hungary' [52.36 $\pm 11 \mathrm{vs} .18 .11 \pm 4.4 \mu \mathrm{mol} \cdot \mathrm{g}^{-1}$ $\mathrm{FW}($ mean $+\mathrm{SD}, \mathrm{n}=3)]$ and the fruit of the $\mathrm{F}_{1}$ to be intermediate $\left[33.6 \pm 8.7 \mu \mathrm{mol} \cdot \mathrm{g}^{-1} \mathrm{FW}(\mathrm{n}=3)\right]$. Further studies are needed to assess the biochemical basis for these differences.

The pumpkin-like fruit shape (corrugated fruit) has been previously used in breeding dual-use ornamental and vegetable capsicums by others (Stommel and Griesbach, 2008), but the inheritance of this trait was not reported in that study. Our results indicated that this trait was controlled by two recessive genes (Table 3). Data consistent with a two-gene model for corrugated fruit were obtained also when an $\mathrm{F}_{2}$ population from 'Round of Hungary' crossed to 'Jalapeno' was analyzed in a different study (C. Christensen, C.I. Wu, and B. Rathinasabapathi, unpublished data). While the nature of the pericarp corrugation could be related to uneven cell division in different regions of the pericarp, our observations suggest that such differential growth happens very early in fruit development as the pumpkin-like shape can be observed as early as 1 week after pollination (data not shown). Because the corrugations develop in a uniform manner, we speculate that the tissues showing differential growth alternate on the pericarp. This trait is the same or highly related to latitudinal fruit trait "lobedness degree" in the study by Yarnes et al. (2013) where eight quantitative trait loci (QTL) on three chromosomes were reported for it.

Previous studies used shape index, defined as ratio of fruit length to fruit diameter, and showed that elongated fruit shape was dominant (Ben-Chaim and Paran, 2000). Other studies have shown fruit shape to be controlled by multiple genes (Chen et al., 2012; Kaiser, 1935; McArdle and Bouwkamp, 1983; Peterson, 1959; Yarnes et al., 2013). By defining fruit shape as round, intermediate, and long based on width:length ratios, we found that the $\mathrm{F}_{2}$ segregation fitted for a single gene with incomplete dominance (Table 4). Although we expect fruit shape to be controlled by multiple loci and is amenable for fine analysis using bioinformatic tools (Brewer et al., 2006), our simplified classifications will be of help for making selections during breeding.

Previous research on the inheritance of pericarp thickness showed thin pericarp to be dominant with large additive variance components (Ben-Chaim and Paran, 2000). The results in the present study confirmed their results, suggesting the involvement of multiple genes (Table 5). In addition, the fruit of 'Round of Hungary' had significantly more and larger cells in the pericarp than the fruit of 'Bulgarian carrot' (Fig. 2), suggesting that genes related to both cell enlargement and division are responsible for the thicker pericarp of the 'Round of Hungary'.

There were high positive correlations of fruit weight with fruit width and pericarp thickness, but no significant correlations with fruit length (Table 6; Fig. 3), which was corroborated by studies by Ben-Chaim and Paran (2000) and Ben-Chaim et al. (2001) who used two inbred lines of pepper 'Maor' and 'Perennial' in their studies. They found that QTL for several fruit traits mapped to the same region in linkage groups 2 and 8 (Ben-Chaim et al., 2001). Barchi et al. (2009) studied a mapping population of peppers generated by a cross of 'Yolo Wonder' and 'Criollo de Morelos 334' and made similar observations. In another study, QTL controlling fruit weight were detected in the same genomic region as that fruit-shape QTL in linkage group 4 (Zygier et al., 2005). Schifriss et al. (1989) stated that fruit weight can be selected independent of fruit shape as they found no significant correlation between fruit shape (length to width ratio) and fruit weight in their study. Further fine analyses are needed to identify the major and minor genes controlling components of the fruit shape.

Barchi et al. (2009) showed that QTL controlling fruit weight, diameter, and pericarp thickness were on chromosome P12 and linked. Such linkage could explain positive correlations between these traits at the phenotypic level. In addition, as 
Table 7. Quantification of carotenoid and carotenoid fatty acid ester levels in pericarp extracts of ripe fruit from Capsicum annuum genotypes 'Bulgarian carrot' (BUC) and 'Round of Hungary' (ROH). Pericarps of equal fresh weight from freshly harvested ripe fruit were extracted as described in the methods section and analyzed using high-performance liquid chromatography followed by electrospray ionization $(+)$ mass spectrometry. Relative levels of compounds in $\mathrm{ROH}$ are expressed as a ratio of average peak areas for $\mathrm{ROH}$ sample divided by the corresponding peak area of that compound in BUC. Some compounds were unique to one genotype and not detectable in the other sample. Numbers in bold indicate compounds that were an order of magnitude $(2 \times$ to $14 \times)$ greater in ROH compared with BUC. Compounds are identified based on molecular weight (MW), absorption at $450 \mathrm{~nm}$, and mean retention time (RT).

\begin{tabular}{|c|c|c|c|c|c|}
\hline MW/tentative identification & $\begin{array}{l}\text { BUC mean } \\
\text { RT (min) }\end{array}$ & $\begin{array}{c}\text { BUC peak } \\
\text { area (counts) }\end{array}$ & $\begin{array}{l}\text { ROH mean } \\
\text { RT (min) }\end{array}$ & $\begin{array}{c}\text { ROH peak } \\
\text { area (counts) }\end{array}$ & $\begin{array}{l}\text { Relative level } \\
\text { in ROH (ratio) }\end{array}$ \\
\hline MW 582 & 23.5 & $12,717,357.4$ & 23.4 & $8,997,169.11$ & 0.71 \\
\hline MW 600-A/capsorubin & 28.2 & $150,212,161$ & 28.8 & $26,396,860.34$ & 0.18 \\
\hline MW 600-B/capsorubin & 30.2 & $639,469,978.7$ & 31.0 & $101,157,392.8$ & 0.16 \\
\hline MW 600-C/capsorubin & 32.9 & $169,018,639.8$ & 32.4 & $90,505,182.64$ & 0.54 \\
\hline MW 598-A & 22.9 & $10,298,126.86$ & 22.9 & $1,681,449.7$ & 0.16 \\
\hline MW 598-B & 36.4 & $83,702,594.04$ & 36.2 & $77,374,963.11$ & 0.92 \\
\hline MW 584/capsanthin & 31.1 & $23,177,504.48$ & 30.1 & $14,015,556.55$ & 0.60 \\
\hline MW 584/capsanthin & 32.4 & $70,439,479.11$ & 31.8 & $225,503,420.6$ & 3.20 \\
\hline MW 584/capsanthin & 34.0 & 0 & 33.6 & $220,553,380.9$ & Unique to $\mathrm{ROH}$ \\
\hline MW 584/capsanthin & 35.3 & $44,715,810.53$ & 35.0 & $96,703,153.02$ & 2.16 \\
\hline MW 584/capsanthin & 38.5 & $117,221,521.9$ & 38.4 & $73,285,566.4$ & 0.63 \\
\hline MW 568/lutein, cis-lutein, zeaxanthin & 35.8 & $91,366,946.46$ & 35.2 & $28,509,620.4$ & 0.31 \\
\hline MW 568/lutein, cis-lutein, zeaxanthin & 38.5 & $24,938,209.81$ & 37.6 & $11,305,728.32$ & 0.45 \\
\hline MW 536/beta-carotene & 40.3 & $3,214,267.586$ & 40.3 & $1,920,943.152$ & 0.60 \\
\hline MW 536/beta-carotene & 41.7 & $33,707,657.6$ & 41.5 & $24,267,441.31$ & 0.72 \\
\hline MW 536/beta-carotene & 51.8 & $17,718,462.75$ & 52.0 & $3,624,468.093$ & 0.20 \\
\hline MW 536/beta-carotene & 53.5 & $156,161,860.6$ & 53.1 & $48,448,909.76$ & 0.31 \\
\hline MW 536/beta-carotene & 56.5 & $12,253,178.59$ & 56.4 & $3,003,669.677$ & 0.25 \\
\hline MW 536/beta-carotene & 65.0 & $47,344,228.98$ & 63.2 & $30,345,251.61$ & 0.64 \\
\hline MW 766/capsanthin ester & 52.0 & $110,260,446$ & 47.4 & $684,706,064.2$ & 6.21 \\
\hline MW 794/capsanthin ester & 51.7 & $125,452,414.7$ & 49.6 & $1,761,717,038$ & 14.04 \\
\hline MW 822/capsanthin ester & 52.0 & 0 & 52.0 & $278,059,117$ & Unique to $\mathrm{ROH}$ \\
\hline MW 948/capsanthin diester & 61.1 & $124,626,777$ & 59.9 & $620,072,103.3$ & 4.98 \\
\hline MW 976/capsanthin diester & 62.6 & $179,087,406$ & 61.2 & $1,505,088,150$ & 8.40 \\
\hline MW 1004/capsanthin diester & 63.7 & $284,661,424.3$ & 63.3 & $1,263,031,684$ & 4.44 \\
\hline MW 1032/capsanthin diester & 65.6 & $130,664,518.9$ & 64.3 & $452,759,069.5$ & 3.47 \\
\hline MW 1060/capsanthin diester & 64.5 & $180,935,251.4$ & 66.0 & & Unique to BUC \\
\hline MW 964/diester & 58.7 & $51,259,362.47$ & 58.0 & & Unique to BUC \\
\hline MW 992/diester & 60.0 & $325,597,805.6$ & 60.0 & & Unique to BUC \\
\hline MW 1020/diester & 61.7 & $461,947,960.9$ & 60.7 & $80,564,392.92$ & 0.17 \\
\hline MW 1048/diester & 63.0 & $310,953,639.7$ & 63.5 & 0 & Unique to BUC \\
\hline MW 1076/diester & 63.7 & $100,048,043.1$ & 63.8 & 0 & Unique to BUC \\
\hline MW 1004/diester & 66.2 & $14,967,543.79$ & 66.0 & 0 & Unique to BUC \\
\hline MW 838/capsorubin monoester & 51.5 & $1221,724,714$ & 52.2 & $46,463,104.94$ & 0.21 \\
\hline
\end{tabular}

suggested by them and other authors, there could be shared mechanisms between fruit development components such as fruit weight, fruit length and width, and pericarp diameter (Barchi et al., 2009; Yarnes et al., 2013).

The inheritance of ripe fruit color has been well studied in Capsicum since the early work of Hurtado-Hernandez and Smith (1985) to the mapping and identification of carotenoid biosynthetic genes (Thorup et al., 2000). In this study, fruit color was evaluated by reflectance spectrophotometry to quantify the lightness and red and yellow color spaces. In the $\mathrm{F}_{2}$ population, four distinct colors were observed: intense red, red orange, yellow orange, and bright yellow. Interestingly, the red color value $\left(+\mathrm{a}^{*}\right)$ was comparable in fruit that were from 'Round of Hungary' and 'Bulgarian carrot' (Fig. 5), but the yellow value $\left(+b^{*}\right)$ was significantly greater in the 'Bulgarian carrot' fruit. The source of the $+\mathrm{a}^{*}$ value in the yellow parent is unknown at present. However, our carotenoid analysis of pericarp extracts suggested that the yellow fruit had detectable amounts of capsanthin, capsorubin, and their fatty acid esters, although lower than in the fruit of 'Round of Hungary' (Table 7), similar to observations in other orange-fruited cultivars (Guzman et al., 2010; Ha et al., 2007; Rodriguez-Uribe et al., 2012). In addition to the colors reported here, occasional development of dark anthocyanin pigmentation in parts of the pericarp of 'Round of Hungary' were observed after ripening; however, this was not observed in all fruit on a plant and such variations could most likely be attributed to environmental factors (data not shown).

Scatter plot analysis showed that the relationships between $+a^{*}$ and $+b^{*}$ values were distinctly different in fruit that had apparent red or red-orange colors from fruit that had apparent yellow or yellow-orange colors (Fig. 5). While there are studies showing that capsanthin and capsorubin fatty acid esters exist in peppers and are of potential value as antioxidants (Matsufuji 
et al., 1998), it is not known how the relative levels of the colored carotenoids, xanthophylls, and fatty acid esters of carotenoids influence the fruit color, appearance, and nutritive value. While the lines developed here are useful for investigating these aspects, this study provides the starting point for breeding lines with improved fruit quality traits.

\section{Literature Cited}

Barchi, L., V. Lefebvre, A. Sage-Palloix, S. Lanteri, and A. Palloix. 2009. QTL analysis of plant development and fruit traits in pepper and performance of selective phenotyping. Theor. Appl. Genet. 118:1157-1171.

Ben-Chaim, A. and I. Paran. 2000. Genetic analysis of quantitative traits in pepper (Capsicum annuum). J. Amer. Soc. Hort. Sci. 125:66-70.

Ben-Chaim, A., I. Paran, R.C. Grube, M. Jahn, R. van Wijk, and J. Peleman. 2001. QTL mapping of fruit-related traits in pepper (Capsicum annuum). Theor. Appl. Genet. 102:1016-1028.

Benzie, I.F.F. and J.J. Strain. 1996. The ferric reducing ability of plasma (FRAP) as a measure of "antioxidant power": The FRAP assay. Anal. Biochem. 239:70-76.

Brewer, M.T., L. Lang, K. Fujimura, N. Dujmovic, S. Gray, and E.V. Knaap. 2006. Development of a controlled vocabulary and software application to analyze fruit shape variation in tomato and other plant species. Plant Physiol. 141:15-25.

Chen, X., R. Fang, R. Zhou, K. Miao, and C. Huang. 2012. Major gene plus polygene inheritance analysis of fruit traits in pepper. Xibei Zhiwu Xuebao 32:246-251.

Crosby, K.M. 2008. Pepper, p. 221-248. In: J. Prohens and F. Nuez (eds.). Handbook of plant breeding. Vegetables II. Springer, New York, NY.

Deshpande, R.B. 1933. Studies in Indian chillies: III. The inheritance of some characters in Capsicum annuum L. Indian J. Agr. Sci. 3:219300.

Guzman, I., S. Hamby, J. Romero, P.W. Bosland, and M.A. O'Connell. 2010. Variability of carotenoid biosynthesis in orange colored Capsicum spp. Plant Sci. 179:49-59.

Ha, S., J. Kim, J. Park, S. Lee, and K. Cho. 2007. A comparison of the carotenoid accumulation in Capsicum varieties that show different ripening colours: Deletion of the capsanthin-capsorubin synthase gene is not a prerequisite for the formation of a yellow pepper. J. Expt. Bot. 58:3135-3144.

Hurtado-Hernandez, H. and P.G. Smith. 1985. Inheritance of mature fruit color in Capsicum annuum L. J. Hered. 76:211213.

Kaiser, S. 1935. The factors governing shape and size in Capsicum fruits: A genetic and developmental analysis. Torrey Bot. Club Bul. 62:433-454.

Khambanonda, I. 1950. Quantitative inheritance of fruit size in red pepper (Capsicum frutescenes L.). Genetics 35:322-343.

López-Raéz, J.A., T. Charnikhova, P. Mulder, W. Kohlen, R. Bino, I. Levin, and H. Bouwmeester. 2008. Susceptibility of the tomato mutant high pigment-2dg (hp-2dg) to Orobanche spp. infection. J. Agr. Food Chem. 56:6326-6332.

Matsufuji, H., H. Nakamura, M. Chino, and M. Takeda. 1998. Antioxidant activity of capsanthin and the fatty acid esters in paprika (Capsicum annuum). J. Agr. Food Chem. 46:34683472.

McArdle, R.N. and J.C. Bouwkamp. 1983. Inheritance of several fruit characters in Capsicum annuum L. J. Hered. 74:125127.

Park, J.H., G.I. Jeon, J.M. Kim, and E. Park. 2012. Antioxidant activity and antiproliferative action of methanol extracts of four different colored bell peppers (Capsicum annuum L.). Food Sci. Biotechnol. 21:543-550.

Peterson, P.A. 1959. Linkage of fruit shape and color genes in Capsicum. Genetics 44:407-419.

Rodriguez-Uribe, L., I. Guzman, W. Rajapakse, R.D. Richins, and M.A. O'Connell. 2012. Carotenoid accumulation in orangepigmented Capsicum annuum fruit, regulated at multiple levels. J. Expt. Bot. 63:517-526.

Sancho, R., C. Lucena, A. Macho, M.A. Calzado, M. Blanco-Molina, A. Minassi, G. Appendino, and E. Munoz. 2002. Immunosuppressive activity of capsaicinoids: Capsiate derived from sweet peppers inhibits $\mathrm{NF}-\kappa \mathrm{B}$ activation and is a potent anti-inflammatory compound in vivo. Eur. J. Immunol. 32:1753-1763.

Schifriss, C., J. Zacks, and A. Goldman. 1989. Some notes on the association between fruit dimensions and fruit weight in Capsicum annuum L. Euphytica 43:275-277.

Sharma, J.R. 1988. Statistical and biometrical techniques in plant breeding. NewAge Intl., New Delhi, India.

Stommel, J.R. and R.J. Griesbach. 2008. Capsicum annuum L. Lil'Pumpkin $^{\mathrm{TM}}$ and Pepper Jack ${ }^{\mathrm{TM}}$. HortScience 43:935-938.

Sun, T., Z. Xu, C.T. Wu, M. Janes, W. Prinyawiwatkul, and H.K. No. 2007. Antioxidant activities of different colored sweet bell peppers (Capsicum annuum L.). J. Food Sci. 72:S98-S102.

Tanksley, S.D. 2004. The genetic, developmental, and molecular bases of fruit size and shape variation in tomato. Plant Cell 16: S181-S189.

Thorup, T.A., B. Tanyolac, K.D. Livingstone, S. Popovsky, I. Paran, and M. Jahn. 2000. Candidate gene analysis of organ pigmentation loci in the Solanaceae. Proc. Natl. Acad. Sci. USA 97:11192-11197.

Tomato Genome Consortium. 2012. The tomato genome sequence provides insights into fleshy fruit evolution. Nature 485:635-641.

Wang, D. and P.W. Bosland. 2006. The genes of Capsicum. HortScience 41:1169-1187.

Yarnes, S.C., H. Ashrafi, S. Reyes-Chin-Wo, T.A. Hill, K.M. Stoffel, and A.V. Deynze. 2013. Identification of QTLs for capsaicinoids, fruit quality, and plant architecture-related traits in an interspecific Capsicum RIL population. Genome 56:61-74.

Zygier, S., A.B. Chaim, A. Efrati, G. Kaluzky, Y. Borovsky, and I. Paran. 2005. QTLs mapping for fruit size and shape in chromosomes 2 and 4 in pepper and a comparison of the pepper QTL map with that of tomato. Theor. Appl. Genet. 111:437-445. 